doi:10.1016/S0278-5846(99)00069-X

1999 Progress in Neuropsychopharmacology and Biological Psychiatry, 23, 1329-1344

\title{
SUBCLINICAL POLYDIPSIA AND POLYURIA IN YOUNG PATIENTS WITH SCHIZOPHRENIA OR OBSESSIVE-COMPULSIVE DISORDER VS NORMAL CONTROLS
}

\author{
ROBERT D. OADES ${ }^{1}$, AND RAINER DANIELS ${ }^{2}$ \\ ${ }^{1}$ Biological Psychiatry Group, University Psychiatry Clinics, Essen, ${ }^{2}$ German Cancer Center, University \\ School of Medicine, Essen, Germany.
}

\begin{abstract}
1. Increased water intake and output is more common among psychiatric patients, especially those with schizophrenia, than in the general population. Animal studies suggest that polydipsia and polyuria derive, in part, from dopamine dysregulation. Stimulated by these observations this study sought to elucidate relationships among water homeostasis, monoamine metabolism, and electrolyte excretion in schizophrenic patients with and without paranoid hallucinatory symptoms (PH vs. NP), thought to reflect hyper- and hypo-dopaminergic states respectively, and to compare these with those shown by patients with obsessive compulsive disorder (OCD).

2. 24hr-urine samples for electrolyte, monoamine and metabolite measures were taken from 14 schizophrenic patients with PH symptoms, 13 with predominantly nonparanoid (NP) symptoms, 11 OCD patients and 27 healthy controls (matched for age, weight and creatinine production). Water intake and serum electrolytes were sampled during psychological testing.

3. $\mathrm{PH}$ patients drank 2-3 times more than the others in a 3-4hr test, yet $24 \mathrm{hr}$-urinary volumes were $75 \%$ larger in both $\mathrm{PH}$ and NP patients than in the two comparison groups.

4. Daily potassium excretion was a bit higher in $\mathrm{PH}$ patients, but concentrations of sodium, potassium and phosphate tended to be lower in PH and NP patients than in the others.

5. Positive associations of electrolyte with homovanillic acid excretion were consistent across groups and not directly related to medication. But associations of electrolyte excretion with noradrenergic activity in controls were absent in psychotic patients and associations with serotonin in OCD patients were absent in the other groups.

6. Increased water intake and output in $\mathrm{PH}$ patients along with the disturbed association with noradrenergic metabolism are consistent with altered autonomic activity in these patients.

7. The independence of measures of water homeostasis from dopaminergic medication indicates that the associations in clinically responding PH patients of polydipsia with DA function (decreased DA levels) may be pertinent to this subgroup but not to schizophrenia in general.
\end{abstract}

Keywords: dopamine, electrolytes, noradrenaline, obsessive-compulsive disorder, paranoia, polydipsia, schizophrenia, serotonin, sodium, urine

Abbreviations: dopamine (DA), homovanillic acid (HVA), 5-hydroxyindoleacetic acid (5-HIAA), 3methoxy-4-hydroxyphenylglycol (MHPG), nonparanoid (NP), noradrenaline (NA), obsessivecompulsive disorder (OCD), paranoid hallucinatory $(\mathrm{PH})$, serotonin $(5-\mathrm{HT})$.

\section{Introduction}

There is a high prevalence for increased drinking and water excretion in patients with schizophrenia (Jose and Perez-Cruet, 1979). Patients who rapidly respond to neuroleptic treatment often show paranoid hallucinatory symptoms and are assumed to be those with increased dopamine (DA) activity (Straube and Oades, 1992). Animal studies have demonstrated the involvement of DA activity 
in polydipsia (Mittelman et al., 1994). Yet it is not clear that a group of schizophrenic patients defined by such symptoms and monoaminergic activity show abnormal water balance. These considerations above would lead one to predict an increased likelihood of polydipsia in paranoid patients. An improved understanding of the physiological and nosological concomitants of polydipsia and polyuria in schizophrenia would aid a basic understanding of the mechanisms of water homeostasis and indicate the extent to which the problems in schizophrenic patients require therapeutic attention.

A high prevalence of polydipsia and polyuria, of about 3-17\% (de Leon et al., 1997) has long been recognized in psychiatric patients, even before the era of neuroleptic treatment (Hoskins and Sleeper, 1933). The problem occurs with a high frequency in patients with schizophrenia, and in $10 \%$ is associated with hyponatremia (Schwartz et al., 1957; Leadbetter et al., 1994). Problems with water homeostasis are also reported in patients with affective illness (Zubenko et al., 1984) but rarely in those with a neurotic disorder (Thomas and Verbalis, 1995). Prevalence varies with the perceived severity of the problem (e.g., 6.6\% with water intoxication and hyponatremia [Jose and Perez-Cruet, 1979] to 50-75\% with polydipsia [Blum et al., 1983; Vieweg et al., 1988; Leadbetter et al., 1994]). Indeed, the severity of the problem varies with symptom severity (Hobson and English, 1963; Zubenko et al., 1984) and ameliorates as symptoms improve (Illowsky and Kirch, 1988). Thus, a good premorbid phase and neuroleptic-response is associated with excess drinking alone (and both clinical features are associated with paranoid schizophrenia), but tardive dyskinesia, tomographic anomalies and negative symptoms are associated with poor water balance and hyponatremia (Lawson et al., 1985; Emsley et al., 1993). Measures of electrolyte and monoamine balance are thus also indicated in studies of patients' control of their water balance.

A link between water imbalance and abnormal mesolimbic monoamine activity has been postulated (Luchins, 1990), but few have looked for associations with measures of monoamine activity. Prell et al. (1996) took lumbar punctures from nine polyuric patients in a group of 39 with chronic schizophrenia: eight of these showed high levels of histamine metabolites and noradrenaline (NA). As urine volumes normalized, so did the amine measures. But they found no association of urine volume with the main monoamine metabolites. Could there be a direct relationship between water-balance and neuroleptic medication? Prell and others dismiss this as most of the patients showed polyuric features prior to medication. Neuroleptics are reported to decrease the high specific gravity of urine from schizophrenic patients (Schultz et al., 1995) and clozapine treatment can improve polydipsia (Henderson and Goff, 1994). But, apart from an association with smoking (Shutty, 1996), few associations for unusual drinking have been sought.

The paucity of reports surprises in view of the association of drinking and of excess or adjunctive drinking in animals (e.g. scheduleinduced-polydipsia) with DA activity (Mittelman et al., 1994). In animals drinking behavior releases mesolimbic DA (Yoshida et al., 1992), yet treatment with DA antagonists can also increase drinking (Missale et al., 1989). But, adjunctive drinking (associated with fixed interval response schedules) is attenuated by DA depletion. However if adjunctive drinking is established before a DA depleting lesion, the manipulation results in prolonged drinking. This may reflect a reduction of the time sharing of the behavior, under DA control (Oades, 1985). Thus if drinking in schizophrenics is sensitive to neuroleptic treatment it may be an adjunctive behavior of postmorbid origin. However there are indications that a second severer type of polydipsia associated with electrolyte imbalance may have a premorbid origin (see clinical associations listed above). Thus, it was important to monitor electrolyte excretion in this report.

The purpose of this explorative study was to sample the drinking habits and urinary volume of a group of young patients without a long history of schizophrenia, to correlate these 
features with symptoms expressed, medication administered and monoamine metabolism and to see if the drinking habits were associated with electrolyte homeostasis. In particular it was hypothesized that splitting the patients with schizophrenia into those actively vs. those not actively expressing paranoid delusions and hallucinations would confirm previous reports of the characters associated with polydipsia with/without poor electrolyte balance (see above).

\section{Methods}

\section{$\underline{\text { Subjects }}$}

Data are presented for 27 patients with a diagnosis of schizophrenia (11.4-24.4 years of age), 11 with OCD (11.1-19.5 years of age: DSM-IIIR, American Psychiatric Association), and 27 healthy age-gender matched control subjects (11.0-24.1 years of age). Diagnosis was made by two ward psychiatrists and confirmed by 4 staff rating video records of an interview to assess positive and negative symptoms (SANS, SAPS: Andreasen, 1983; 1984). A group with marked paranoid hallucinatory symptoms $(\mathrm{PH})$ and a nonparanoid group (NP) without marked positive symptoms were formed by a median split for combined SAPS scores for paranoid delusions and hallucinations (a score of 7). The two groups had similar levels of negative symptoms (Table 1: Oades et al., 1994). Symptom severity was recorded with the brief psychiatric rating scale (BPRS). First admissions included 9/14 $\mathrm{PH}$ and 8/13 NP patients. The OCD patients were not receiving medication, and apart from a case of trichotillomania showed no other comorbid diagnoses. OCD patients were included as a comparison group firstly because they show related but different biological dysfunction (e.g. orbital vs. dorsolateral frontal cortex, serotonin vs. dopamine activity: Oades et al., 1994), and secondly because psychotic patients often develop through an obsessivecompulsive phase when young and a proportion retain these features later (Dowling et al., 1995). The controls reported no history of major illness, or psychiatric consultation and were free of prescriptive medication. Testing followed the approval of the protocol by the management of the psychiatry clinics, the agreement of the clinic staff in each case and the cooperation, understanding and consent of the child and legally responsible adult.

\section{Procedure}

Neuropsychological tests were presented on two separate days and lasted for 3 hours (183 min S.D. 83): a $24 \mathrm{hr}$-urine sample was collected on the day between tests (Oades et al., 1994). Drinking was allowed in the pauses between tests. While the experimenter prepared the next test, it was suggested that the subject could turn away from the computer, rest the eyes and have a drink if thirsty. A previously measured volume of water was presented in a normal drinking glass. A measuring cylinder was used to record the amount left after drinking at the end of the session. Fluid intake was not controlled in the period immediately prior to the test but on questioning was found to have consisted usually of about $200 \mathrm{ml}$ of liquid taken with breakfast over an hour before. The duration of the test session was recorded to the nearest minute. 
Table 1

Demographic and Clinical Data (mean + S.D.)

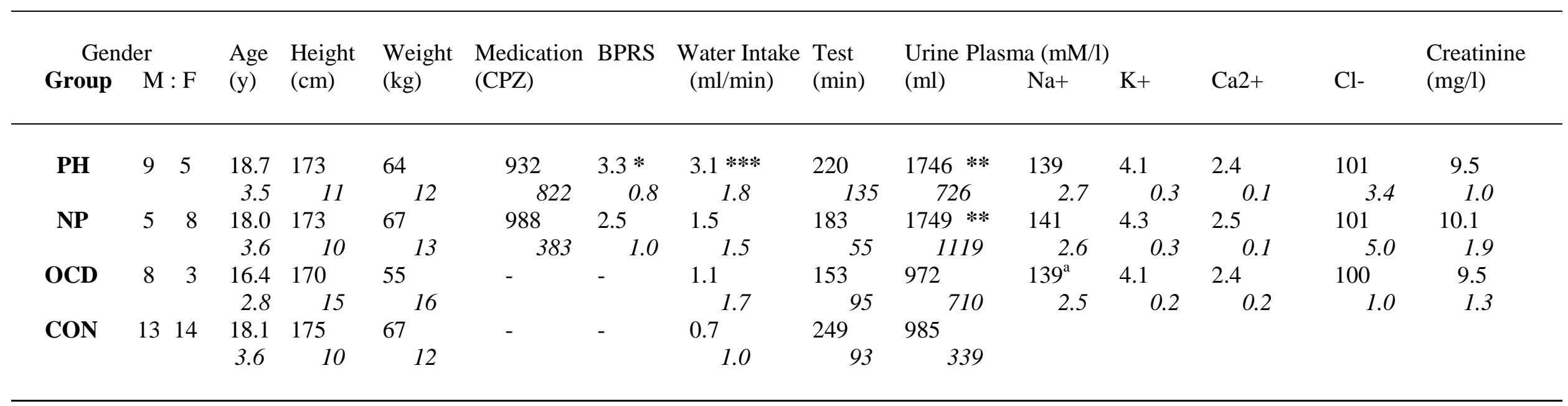

$\mathrm{CPZ}=$ chlorpromazine equivalents, $\mathrm{BPRS}=$ Brief Psychiatric Rating Scale (score per question for 18 questions with ratings 1-7), a = measures from 5 OCD patients (clinical routine measures were not taken as OCD patients received no medication). No significant differences for age (4 groups) or medication (PH vs. $\mathrm{NP}$ ): $* \mathrm{p}<0.06$ (t-test); $* * \mathrm{p}<0.02$ (vs. CON), $<0.07$ (vs. OCD, Scheffe tests): *** p $<0.0002$ (vs. CON), p $<0.02$ (vs. OCD), p $<0.06$ (vs. NP, Scheffe tests) 


\section{Biochemical Measures}

$D A$, noradrenaline (NA), serotonin $(5 \mathrm{HT})$ and their metabolites (homovanillic acid, HVA; 3-methoxy-4-hydroxyphenylglycol, MHPG; 5hydroxyindoleacetic acid, 5HIAA) were measured in $24 \mathrm{~h}$ urine collections from all subjects on a low monoamine diet, as described (Oades et al., 1994). Briefly, acidified samples were frozen until analysis with ion exchange liquid chromatography and fluorescence detection. Volume-adjusted measures were expressed as nanograms per gram creatinine per square meter body area to correct for general somatic metabolic rates and variations of body size.

Sodium and potassium in urine were analyzed by flame emission spectroscopy with a lithium reference and calcium with atomic absorption spectrophotometry (Beckman, Fullerton, U.S.A.). Using a Hitachi 704 automatic analyzer inorganic phosphate was determined by ultraviolet detection using the molybdate reaction and creatinine was measured with the picric acid reaction using modified fixed-time kinetics. The variability between samples ranged as follows: sodium, 3-10\%; potassium, 0-13\%, calcium, 1-15\%; phosphate, $3-17 \%$ and creatinine, $2-13 \%$. In the patient group routine blood samples were also analyzed for sodium, potassium, calcium and chloride.

\section{Data Analyses}

The distribution of the data, while not homogeneous, did not differ significantly from normal (e.g., Kolmogorov-Smirnov for sodium, $d=0.075$, for phosphate $d=0.093$ ). Initially a parametric multivariate analysis of variance was performed across groups and similar types of electrolyte measures. This was followed by one-way analyses of variance where the locus of the difference was confirmed by the conservative Scheffe test ( $\alpha$ $=0.05)$ : the covariates were creatinine concentration, as an index of metabolism, and then urine volume to control for water excretion. Following the establishment of group differences Pearson correlation coefficients were sought for medication, symptom severity and for water in/output. In view of group differences in monoamine and electrolyte excretion, associations were also explored between these measures with uncorrected Pearson correlation coefficients where a significance of $0.05>p>0.01$ is regarded as a trend.

\section{Results}

\section{Drinking Behavior}

There were no significant differences between groups for the time-period over which drinking was recorded (2.5 to $4 \mathrm{hr}$, Table 1). Water intake did not relate to age or weight in any group. However the groups did differ on water intake $(F[3,59]=8.6, p<$ $0.0001)$. The $\mathrm{PH}$ group drank three times more water than the OCD or the healthy groups (Scheffe $p=0.013-0.0001$, respectively: Table 1) and slightly more than the NP patients ( $p=$ 0.059: Table 1).

Urine Volume: Relations with Age, Weight, Creatinine and Drinking

The control measures are considered first. Urine volume correlated with age only in the OCD group that contained the youngest and smallest subjects $(r=+0.6, p<0.05)$, but correlated with weight in both comparison groups ( $r=+0.4$ to $+0.6, p=0.05)$. Bodyweight correlated with daily creatinine production (controls, $r=+0.7, p<0.001$; OCD, $r=0.6, p=0.04$; schizophrenia, $r=+0.4, p=$ $0.06)$. The weaker relation in patients could reflect on the reliability of the urine collection, but as subjects were supervised, were closely matched for age and weight, and had similar creatinine production (with weight as covariate, $F[3,59]=0.48, p=0.7)$, it can reasonably be assumed that collection was not a major source of error and that collections were complete.

Both $\mathrm{PH}$ and NP groups excreted more urine than the controls $(F[3,61]=6.3, p<0.001)$, with a trend for more than in the OCD group (Table 1). Covarying for weight did not materially alter this result $(F[3,59]=5.8)$. Drinking and urine volumes were not significantly associated in any of the four 
groups ( $r=-0.25$ [controls] to +0.35 [NP]), nor did they relate to creatinine concentrations. (As expected, overall creatinine production correlated with drinking and urine volumes: $r$ $=+0.39$ and $-0.32, \mathrm{p} \leq 0.01$, respectively, $\mathrm{n}=$ 64.)

The volume drunk by the $\mathrm{PH}$ and NP groups did not relate to either the symptom severity (BPRS: $r=+0.27$ to -0.13 ) nor the amount of medication received (chlorpromazine equivalents: $r=+0.2$ to -0.06 ). Separate consideration of the five patients on clozapine vs. the 18 on similar levels of typical neuroleptics (1128 vs. 1119 chlorpromazine equivalents) did not alter the picture $(r=+0.3$ to $+0.1, p<0.6)$. But for the $\mathrm{PH}$ group, alone, the more severe the BPRS symptoms, the less urine was excreted $(r=-0.64, p=0.024)$.

\section{Concentrations and Excretion Rates of Urinary Electrolytes}

A two-way MANCOVA of the electrolyte concentrations in four subject groups covarying for urine volumes was significant ( $F$ $[3,59]=3.04, p=0.035)$. This was accounted for only by the decreased sodium concentration in PH and NP patients (Scheffe $\mathrm{p}<0.02$ ). Table 2 shows that sodium levels were lowest in NP patients, and that electrolyte concentrations were especially high in the OCD group.

The daily excretion rate of sodium (per kg per day) in $\mathrm{PH}$ patients did not differ from the other groups $(F[3,59]=1.53, p=0.2)$, but they did tend to excrete more potassium per day $(F[3,59]=2.5, p=0.069$; Scheffe $p=0.08$ : Fig. 1). Interestingly, using the high volume of urine as a covariate, $\mathrm{PH}$ patients seemed to excrete sodium faster, per unit volume, ( $F[3$, 58 ] $=3.55, p<0.02$; \# in Fig. 1). This may be misleading in terms of electrolyte homeostasis, but indicates the stress on the system when $\mathrm{PH}$ patients drink and excrete more water.
Relations Between Urinary Electrolyte and Monoamine Excretion

Urinary levels of monoamines and their metabolites in these subjects have been reported (Oades et al., 1994). Briefly, with respect to controls, OCD patients showed high levels of HVA, 5-HT and 5-HIAA, PH patients excreted high levels of HVA, MHPG and 5HIAA, while NP patients excreted high levels of 5-HIAA alone. We explored correlations of these measures, utilization and inter-amine ratios, first with water in/output, and second with electrolytes to see if there was any basis for an association between the group differences reported for monoamines and electrolytes.

Monoamines: Water Intake and Output: The only monoamine measure associated with drinking was DA and its ratio to NA for the $\mathrm{PH}$ patients $(r=-0.6, p=0.023)$. DA-related measures were not related to the volume of urine in any group, but each of the other amines tended to be correlated inversely to volume, in separate groups (adrenaline for NP, $[r=-0.56, p<0.05], 5-H T$ for OCD [ $r=-0.71, p$ $<0.02]$ and NA for controls $[r=-0.44, p=$ 0.02 ]: Fig. 2).

Catecholamine and Electrolyte Measures: Activity and electrolyte measures were differentially related in $\mathrm{PH}$ vs. comparison groups. Thus, in control and OCD groups sodium concentrations and DA utilization were positively correlated $(r=+0.4$ to +0.7 , $0.04>p>0.01$ ), but the association with NA metabolism (MHPG), though positive in OCD patients $(r=+0.6, p=0.04)$, was negative in controls $(r=-0.5, p=0.01)$. In contrast, while the low sodium levels in NP patients correlated with DA utilization, in $\mathrm{PH}$ patients they tended to correlate only with adrenaline (both $r=+0.6, p=0.04$ ). Adrenaline was negatively associated with calcium (NP and $\mathrm{PH})$ and phosphate excretion (PH) $(r=-0.6$ to $0.7,0.04>p>0.009$ ). (The neuroleptic dose in chlorpromazine equivalents correlated only with calcium excretion rates, and this only in the NP patients $[r=+0.63, p=0.02]$ ). 
Table 2

Electrolyte Concentration in 24hr-Urine Samples (mean + S.D.)

\begin{tabular}{cccccc}
\hline & $\begin{array}{c}\text { Creatinine } \\
\mathrm{mg} / \mathrm{l}\end{array}$ & $\begin{array}{l}\text { Sodium } \\
\mathrm{mM} / \mathrm{l}\end{array}$ & $\begin{array}{l}\text { Potassium } \\
\mathrm{mM} / \mathrm{l}\end{array}$ & $\begin{array}{l}\text { Calcium } \\
\mathrm{mg} / \mathrm{l}\end{array}$ & $\begin{array}{l}\text { Phosphate } \\
\mathrm{mg} / \mathrm{l}\end{array}$ \\
\hline $\begin{array}{c}\text { Group } \\
\text { PH }\end{array}$ & 854 & 88.7 & 45.9 & 417 & 646 \\
$\mathrm{n}=14$ & 413 & 38.1 & 16.6 & 294 & 236 \\
$\mathbf{N P}$ & 930 & 77.0 & 43.1 & 302 & 580 \\
$\mathrm{n}=13$ & 426 & 50.1 & 22.8 & 189 & 229 \\
OCD & 1741 & $150.7 * *$ & 72.4 & 598 & 991 \\
$\mathrm{n}=11$ & 1130 & 56.1 & 32.1 & 332 & 524 \\
$\mathbf{C O N}_{\mathrm{n}=27}$ & 1559 & $128.7 *$ & 57.4 & 501 & 918 \\
& 617 & 47.8 & 30.1 & 363 & 363 \\
\hline
\end{tabular}

Scheffe test following significant MANCOVA with urine volume as covariate, - * PH and NP, respectively, vs CON p=0.09 and $\mathrm{p}=0.02$, ** $\mathrm{PH}$ and $\mathrm{NP}$, respectively vs $\mathrm{OCD}, \mathrm{p}=0.02$ and $\mathrm{p}=0.003$, see text.

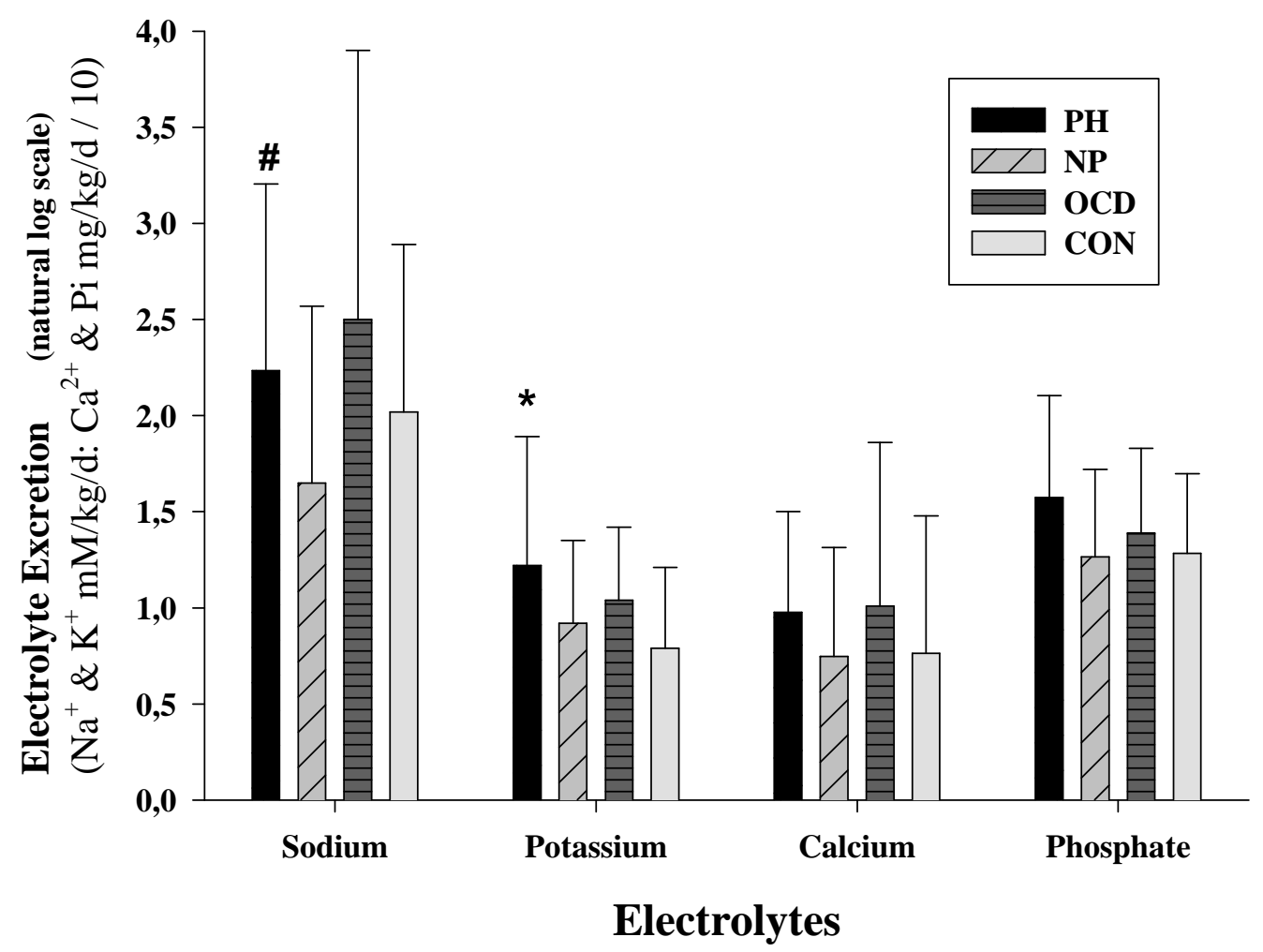

Fig. 1. Rate of Electrolyte Excretion (per kg body weight per day): Patients with Schizophrenia with $(\mathrm{PH})$ and without paranoid hallucinatory symptoms (NP), obsessive-compulsive disorder (OCD) and Healthy Controls (CON) [\#, see text: $* \mathrm{p}<0.08$ trend $\mathrm{PH}>\mathrm{CON}$ ] 
Noradrenaline Levels vs. $24 \mathrm{hr}$ Urine Volume

Healthy Controls (27): $r=-0.44, p=0.02$

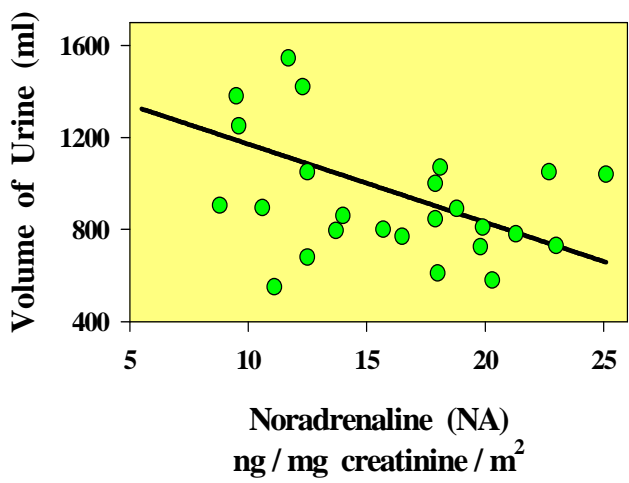

DA/NA Ratio (24 hr Urine) $v s$. Rate of Drinking PH Patients (14): $r=-0.69, p=0.023$

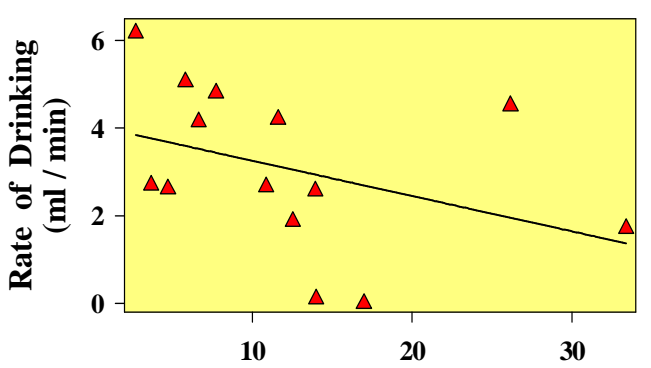

Ratio of Dopamine (DA) / Noradrenaline (NA)
Serotonin Levels vs. $24 \mathrm{hr}$ Urine Volume

OCD Patients (11): $r=-0.71, p=0.015$

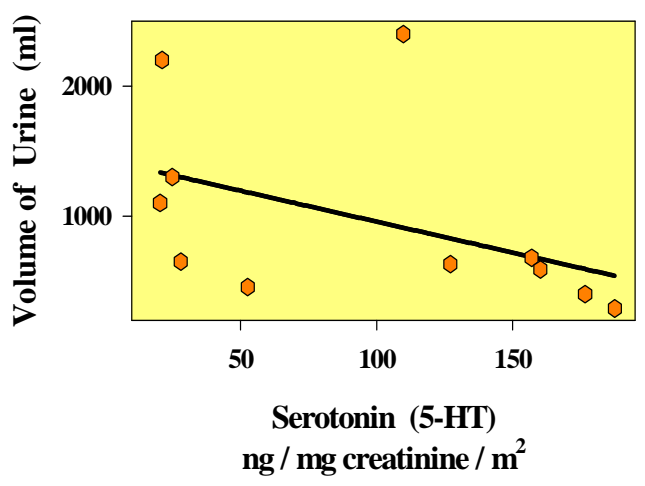

Adrenaline Levels vs. $24 \mathrm{hr}$ Urine Volume NP Patients (13): $r=-0.56, p=0.048$

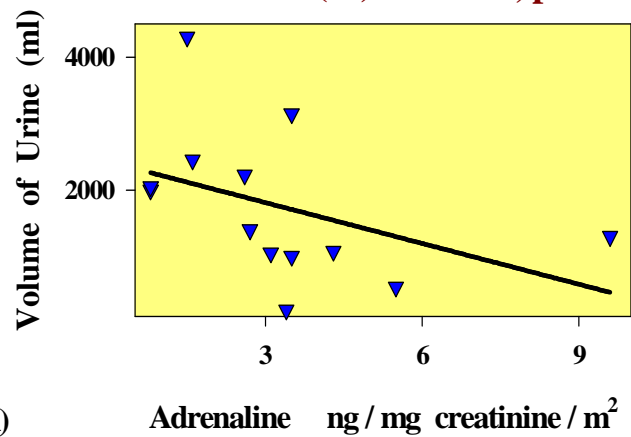

Fig. 2. Correlations of noradrenaline, serotonin and adrenaline with water-excretion volumes

(top and bottom right) and the DA/NA ratio with drinking (bottom left) in different subject groups.

Indoleamine and Electrolyte Measures: Indoleamine measures were related to separate electrolytes in each group. In controls both 5-HT and 5-HIAA levels showed trend correlations with potassium excretion ( $r$ $=+0.43, \mathrm{p}=0.028$ ). For NP patients $5-\mathrm{HT}$ utilization tended to correlate negatively and only with calcium concentration and excretion $(r=-0.7, p<0.02)$. But, in PH patients $5-H T$ was associated with sodium concentration and excretion ( $r=+0.76, p=0.002)$. Levels of each electrolyte were related negatively to $5-\mathrm{HT}$ levels in OCD patients $(r=-0.6$ to $-0.8, p=0.05$ to 0.002 ).

\section{Summary: Urine Analysis}

These results suggest, first, that DA activity and sodium excretion may be altered in patients with schizophrenia, and this may depend indirectly on neuroleptic medication as indicated by the differential clinical response in terms of positive and negative symptoms; but the balance for other electrolytes was independent of medication effects. Second, factors influencing unusual electrolyte excretion and NA activity may be held in common and may relate to features of the psychotic illness (e.g., PH subgroup). Third, the relationship of 5-HT to potassium and phosphate excretion, peculiar to the $O C D$ group, emphasizes the likelihood of a common underlying association to this illness (cf. sensitivity to serotonin uptake blockers in OCD: Greist et al., 1995). 


\section{Discussion}

The main findings were that both PH and NP patients with schizophrenia excreted larger volumes of urine than OCD or healthy subjects, but only the $\mathrm{PH}$ patients drank more water. Water intake and output were not related. The finding of polyuria is consistent with many reports on psychotic patients (see introduction), but the demonstration of increased water output in a non-selected group of young schizophrenic patients is novel. The restriction of increased rates of drinking to patients with $\mathrm{PH}$ symptoms was predicted and is consistent with reports of increased water intake in rodents chronically treated with amphetamine (Nencini and Fraioli, 1994), a model for paranoid schizophrenia (Connell, 1958), and in patients with amphetamine-induced psychosis (Änggard et al., 1970).

\section{Water Intake and Output: Symptoms}

The measure of drinking used should only be regarded as an indicator of water needs. Recorded over two periods of laboratory testing it may be viewed as a challenge of thirst sensitivity. Attempts at replication of our findings should control for daily water intake. By our measure drinking was increased in $\mathrm{PH}$ patients independent of symptom severity or levels of medication. Like drinking behavior, water output was unrelated to the level of medication; but unlike drinking it was related to the severity of symptoms. This relationship was only seen in the $\mathrm{PH}$ patients who were also drinking more. Unexpectedly, this relationship was a negative one, that is to say the more severely ill excreted less. Superficially this appears to contrast with claims that polydipsia is exaggerated in the severely ill and decreases as symptoms improve (llowsky and Kirch, 1988). However, to date this has been based on increased water output and the assumption of a simple relationship of urine volume with water intake.

In contrast to the chronically-ill patients described in the above studies, our patients were young and at a relatively acute stage of their illness where clinical symptoms were in the process of responding to medication, a feature especially likely in those with $\mathrm{PH}$ symptoms (Straube and Oades, 1992). Alternative explanations in terms of the reliability of sample collection are unlikely. It seems improbable that an artifact should affect the one type of patient more than the other, where collections were supervised by ward personnel. Further, patterns of drinking and excretion were quite different and specific in a similar study run at the same time with healthy and attention-deficit disorder children (ADHD: Oades et al., 1998). Here, the urine volumes were higher in one group than another (schizophrenics vs. OCD), but only the $\mathrm{PH}$ sub-group drank more. In contrast, ADHD children drank more than normal yet produced less urine. Further reasons for confidence in the collections include the close matching of age and weight of the subjects and that the daily excretion levels of creatinine did not differ between groups.

\section{Role of Electrolyte Homeostasis}

Considering that hyponatremia is one wellknown etiological explanation of polydipsia (Illowsky and Kirch, 1988; Patel, 1994), were there any associations of electrolytes with our measures of water intake and output? Of the low concentrations of sodium, potassium, calcium and phosphate in samples from both schizophrenic groups, only sodium levels remained low after taking urine volumes into account. Indeed in the $\mathrm{PH}$ group, excretion rates (per kg body weight) were on average normal for sodium and a bit higher for potassium. Taking into consideration that serum electrolyte measures were normal, there was no evidence for hyponatremia in the present sample of patients. However, this close look at the data does suggest, in $\mathrm{PH}$ patients with a higher than normal water intake and output, that the electrolyte homeostasis was stressed. This is consistent with a recent report of marginal correlations between positive symptoms and plasma sodium levels in extreme examples of polyuria (Goldman et al., 1997). 
Dopamine/Neuroleptic Treatment:

\section{Adjunctive Behavior and Renal Mechanisms}

In view of the association between DA and drinking reported in animal studies (see introduction), it is remarkable that the only association with drinking found here was for $\mathrm{PH}$ patients and DA (and DA/NA ratio). In these patients DA levels were depressed, HVA increased and NA levels unchanged. These data are consistent with the view that drinking was present as an adjunct to other behavior prior to neuroleptic treatment, but that medication (in clinically responding $\mathrm{PH}$ patients) led to increased DA activity and possibly to increased drinking (cf. introduction). If confirmed this implies that neuroleptic effects are indirect, indeed an epiphenomenon to the increase of drinking. It should be noted that the primary renal effects of DA agents are on the renal vasculature and sodium tubular transport and mediated via D1 receptors (Lee, 1993). The DA D2 contribution results in a reduction of sodium release. DA D2 effects may also occur via a central osmostat and be reflected in increased vasopressin release (Goldman et al., 1988). While the present study is limited by the absence of measures of vasopressin, the relation to DA and DA/NA ratios is consistent with this background and may reflect central DA D2 sensitivity, as reported in rodent studies (Fraioli et al., 1998). In further support of an epiphenomenal explanation, it may be noted that urine volumes related to the excretion of a different monoamine in each group of subjects. The features reported to relate to excess drinking alone, (as opposed to hyponatremia) pertain to the $\mathrm{PH}$ patients studied here (Lawson et al., 1985; Emsley et al., 1993).

\section{Noradrenaline, Adrenaline and Autonomic Activity}

Do monoamine electrolyte relationships provide any further indication of the influences underlying polyuria in these patients? DA utilization was positively related to sodium excretion in controls and NP patients. The implication for NP patients with a poor clinical response to neuroleptic medication is borne out by relatively low levels of electrolyte excretion. An effect in terms of polyuria is presumably held in check by the relatively high levels of adrenaline excreted, that were negatively associated with urine volume. The absence of a volume/adrenaline but the presence of a sodium/adrenaline association in $\mathrm{PH}$ patients, along with the negative association of urine volume with the relatively high NA levels seems likely to contribute to the presence of polydipsia/polyuria in patients with $\mathrm{PH}$ symptoms. Further, the negative relationship of NA excretion to sodium levels in controls was not seen in PH patients. Thus, it is argued that the increase of NA activity reflected by increased MHPG excretion in PH patients and reflecting increased autonomic activity (Beuger et al., 1995) may be associated with poor water homeostasis (Lee 1993). This explanation is consistent with the high levels of NA in the CSF of polyuric chronic schizophrenics (Prell et al., 1996). Indeed, to underline this relationship, these NA levels normalized as the urine volumes returned to normal. In a similar vein, Greendyke et al. (1998) reported that $7 / 14$ polyuric schizophrenic patients responded to the inhibitory noradrenergic agent clonidine with decreased urine production.

\section{Conclusions}

A study of water intake and output showed that non-pathological levels of polyuria are widespread among schizophrenic but not OCD patients. A challenge test of drinking behavior indicated that $\mathrm{PH}$ patients were prone to show a polydipsia that may be related to DA activity. However, in the presence of relationships to NA levels, in the absence of relationships to neuroleptic medication and the consistency of electrolyte-HVA relationships across groups it is argued that the susceptibility of PH patients to drinking is related to increased levels of autonomic arousal.

\section{Acknowledgements}

The authors are very grateful to, $\mathrm{Dr} \mathrm{H}$. Bussemas of the Laboratory Dr. Eberhard, Dortmund, for the monoamine analysis and thank Professor C. Eggers, Dr. M. Möllering and PD Dr. R. Schepker for their interest and 
clinical help.

\section{References}

AMERICAN PSYCHIATRIC ASSOCIATION. (1987) Diagnostic and Statistical Manual of Mental Disorders, Third Edition, Revised. American Psychiatric Association, Washington, DC.

ANDREASEN, N. C. (1983) The scale for the assessment of negative symptoms (SANS). University of lowa, lowa City, IA.

ANDEASEN, N. C. (1984) The scale for the assessment of positive symptoms (SAPS). University of lowa, lowa City, IA.

ÄNGGARD, E., GUNNE, L-M., JÖNSSON, L-E. and NIKLASSON, F. (1970) Pharmacokinetic and clinical studies on amphetamine dependent subjects. Eur. J. Clin. Pharmacol. 3: 3-11

BEUGER, M., VAN KAMMEN, D. P., YAO, Y. K. and KELLEY, M. E. (1995) Dopamine turnover in schizophrenia before and after haloperidol withdrawal; CSF, plasma and urine studies. Schizophr. Res. 15: 72.

BLUM, A., TEMPEY, F. W. and LYNCH, W. J. (1983) Somatic findings in patients with psychogenic polydipsia. J. Clin. Psychiatry 44: 55-56.

CONNELL, P. (1958) Amphetamine psychosis.; Chapman \& Hall, London.

DE LEON, J., VERGHESE, C., TRACY, J. I., JOSIASSEN, R. C. and SIMPSON, G. M. (1997) Polydipsia and water intoxication in psychiatric patients: A review of the epidemiological literature. Biol. Psychiatry 35: 408-419.

DOWLING, F. G., PATO, M. T. and PATO, C. N. (1995) Comorbidity of obsessivecompulsive and psychotic symptoms: A review. Harvard Rev. Psychiatry 3 : 75-83.

EMSLEY, R. A., SPANGENBERG, J. J., ROBERTS, C., TALJAARD, F. J. J. and CHALTON, D. (1993) Disordered water homeostasis and cognitive impairment in schizophrenia. Biol. Psychiatry 34: 630-633.

FRAIOLI, S., CIOLI, I. and NENCINI, P. (1998) Amphetamine reinstates polydipsia induced by chronic exposure to quinpirole, a dopaminergic D2 agonist, in rats. Behav. Brain Res. 89: 199-215.

GOLDMAN, M. B., LUCHINS, D. J. and ROBERTSON, G. L. (1988) Mechanisms of altered water metabolism in psychotic patients with polydipsia and hyponatremia. N. Engl. J. Med. 318: 397-403.

GOLDMAN, M. B., ROBERTSON, G. L., LUCHINS, D. J., HEDEKER, D. and PANDEY, G. D. (1997) Psychotic exacerbations and enhanced vasopressin secretion in schizophrenic patients with hyponatremia and polydipsia. Arch. Gen. Psychiatry 54: 443-449.

GREENDYKE, R. M., BERHARDT, A. J., TASBAS, H. E. and LEWANDOWSKY, K. S. (1998) Polydipsia in chronic psychiatric patients: Therapeutic trials of clonidine and enalapril. Neuropsychopharmacol. 18: 272281.

GREIST, J. H., JEFFERSON, J. W., KOBAK, K. A., KATZELNICK, D. J. and SERLIN, R. C. (1995) Efficacy and tolerability of serotonin transport inhibitors in obsessivecompulsive disorder. Arch. Gen. Psychiatry 52: 53-60.

HENDERSON, D. C. and GOFF, D. C. (1994) Clozapine for polydipsia and hyponatremia in chronic schizophrenics. Biol. Psychiatry 36: 768-770.

HOBSON, J. A. and ENGLISH, J. T. (1963) Selfinduced water-intoxication. Ann. Int. Med. 58: 324-332.

HOSKINS, R. G. and SLEEPER, F. H. (1933) Organic functions in schizophrenia. Arch. Neurol. Psychiatry 30: 123-140.

ILLOWSKY, B. P. and KIRCH, D. G. (1988) Polydipsia and hyponatremia in psychiatric patients. Am. J. Psychiatry 145: 923-925. 
JOSE, C. J. and PEREZ-CRUET, J. (1979) Incidence and morbidity of self-induced water intoxication in state mental hospital patients. Am. J. Psychiatry 136: 221-222.

LAWSON, W. B., KARSON, C. N. and BIGELOW, L. B. (1985) Increased urine volume in chronic schizophrenic patients. Psychiatry Res. 14: 323-331.

LEADBETTER, R. A., SHUTTY, M. S., HIGGINS, P. B. and PAVLONIS, D. (1994) Multidisciplinary approach to psychosis, intermittent hyponatremia and polydipsia. Schizophr. Bull. 20: 375-385.

LEE, M. R. (1993) Dopamine and the kidney: 10 years on. Clin. Science 84: 357-375

LUCHINS, D. J. (1990) A possible role of hippocampal dysfunction in schizophrenic symptomatology. Biol. Psychiatry 28: 8791.

MISSALE, C., LOMBARDI, C., DE CORTIS, R., MEMO, M., CARRUBA, M. O. and SPANO, P. F. (1989) Dopaminergic mechanisms modulating the renin-angiotensin system and aldosterone secretion: an overview. J. Cardiovasc. Pharmacol. 14 (suppl. 8): 2939.

MITTELMAN, G., ROSNER, A. L. and SCHAUB, C. L. (1994) Polydipsia and dopamine: Behavioral effects of dopamine D1 and D2 receptor agonists and antagonists. J. Pharmacol. Exp. Ther. 271: 638-650.

NENCINI, P. and FRAIOLI, S. (1994) Environment-specific reinstatement of amphetamine-mediated hyperdipsia by morphine and (-)-norpseudoephedrine. Pharmacol. Biochem. Behav. 47: 339-343

OADES, R. D. (1985) The role of noradrenaline in tuning and dopamine in switching between signals in the CNS. Neurosci. Biobehav. Rev. 9: 261-282.

OADES, R. D., RÖPCKE, B. and EGGERS, C. (1994) Monoamine activity reflected in urine of young patients with obsessive compulsive disorder, psychosis with and without reality distortion and healthy subjects: An explorative analysis. J. Neur. Transm. 96: 143-159.

OADES, R. D., DANIELS, R. and RASCHER, W. (1998) Plasma neuro-peptide-Y levels, monoamine metabolism, electrolyte excretion and drinking behavior in children with attention-deficit hyperactivity disorder. Psychiatry Res. 80: 177-186.

PATEL, J. K. (1994) Polydipsia, hyponatremia and water intoxication among psychiatric patients. Hosp. Community Psychiatry 45 : 1073-1074.

PRELL, G. D., GREEN, J. P., ELKASHEF, A. M., KHANDELWAL, J. K., LINNOILA, M., WYATT, R. J., LAWSON, W. B., JAEGER, A. C., KAUFFMANN, C. A. and KIRCH, D. G. (1996) The relationship between urine excretion and biogenic amines and their metabolites in cerebrospinal fluid of schizophrenic patients. Schizophr. Res. 19: 171-176.

SCHULTZ, S. K., TRAVIS, K., EIBELL, S., MILLER, D., ARNDT, S. V. and ANDREASEN, N. C. (1995) Polydipsia and schizophrenia: A comparison of neuroleptic-naive and treated patients. Schizophr. Res. 15: 165.

SCHWARTZ, W. B., BENNETT, W. and CURELOP, S. (1957) A syndrome of renal sodium loss and hyponatremia probably resulting from inappropriate secretion of antidiuretic hormone. Am. J. Med. 23: 529542.

SHUTTY, M. S. (1996) Cigarette use, drinking and voiding in schizophrenic patients with polydipsia and hyponatremia. Schizophr. Res. 21: 195-197.

STRAUBE, E. R. and OADES, R. D. (1992) Schizophrenia: Empirical research and findings. Academic Press, San Diego, CA.

THOMAS, A. and VERBALIS, J. G. (1995) Hyponatremia and the syndrome of inappropriate antidiuretic hormone secretion associated with drug therapy in psychiatric patients. CNS Drugs 4: 357-369. 
VIEWEG, W. V. R., HUNDLEY, P. L., GODLESKI, L. S., TISDELLE, D. A., PRUZINSKY, T. and YANK, G. R. (1988) Similarity of patterns of urine excretion among nonpolyuric and polyuric patients with thought disorders. Schizophr. Res. 1: 295-298.

YOSHIDA, M., YOKOO, H., MIZOGUCHI, K., KAWAHARA, H., TSUDA, A., NISHIKAWA, T. and TANAKA, M. (1992) Eating and drinking cause increased dopamine release in the nucleus accumbens and ventral tegmental area in the rat: Measurement by in vivo microdialysis. Neurosci. Lett. 139: 73-76.

ZUBENKO, G. S., ALTRESMAN, R. I., CASSIDY, J. W. and BARREIRA, P. J. (1984) Disturbances of thirst and water homeostasis in patients with affective illness. Am. J. Psychiatry 141: 436-437. 